\title{
Recyclable waste separation system based on material classification using weight and size of waste
}

\author{
Nur Shahida Midi, Muhammad Aizat Rahmad, Siti Hajar Yusoff, Sarah Yasmin Mohamad \\ Department of Electrical and Computer Engineering, International Islamic University Malaysia, Malaysia
}

\begin{tabular}{|c|c|}
\hline Article Info & ABSTRACT \\
\hline Article history: & \multirow{10}{*}{$\begin{array}{l}\text { Insufficient landfills problem had increased the needs to decrease the waste } \\
\text { and recycling them. However, despite the efforts done by the government } \\
\text { and local authorities on promoting recycling culture by introducing new laws } \\
\text { and regulations, the awareness and willingness among the community is still } \\
\text { low. One of the possible reasons to this is lack of effort to categorize the } \\
\text { waste into the designated category which are paper, glass, plastic and metal. } \\
\text { In order to address this problem, it is important to design a system that will } \\
\text { ease the process of categorizing the waste. This can be achieve by the } \\
\text { automation of the said process. In this work, a system consist of an algorithm } \\
\text { and hardware to automatically categorize recyclable waste is proposed. The } \\
\text { proposed system are utilizing weight sensor and ultrasonic sensors in order to } \\
\text { capture the characteristics of the waste item, which are weight and size so } \\
\text { that it can be categorized into paper, glass, plastic and metal. Here, a sytem } \\
\text { to automatically separate household waste item is presented by combining an } \\
\text { algorithm with a set of hardware consist of minimal number of sensors, } \\
\text { conveyer belt and servor motors. }\end{array}$} \\
\hline Received Dec 27, 2018 & \\
\hline Revised Feb 14, 2019 & \\
\hline Accepted Mar 15, 2019 & \\
\hline Keywords: & \\
\hline Material classification & \\
\hline Recyclable waste & \\
\hline Ultrasonic sensor & \\
\hline Waste separation & \\
\hline Weight sensor & \\
\hline
\end{tabular}

Copyright $@ 2019$ Institute of Advanced Engineering and Science. All rights reserved.

\section{Corresponding Author:}

Nur Shahida Midi,

Department of Electrical and Computer Engineering,

International Islamic Univesity Malaysia,

Jalan Gombak, 53100 Kuala Lumpur, Malaysia.

Email: nurshahida@iium.edu.my

\section{INTRODUCTION}

The raising number of population and development of an area comes with various side effect. One of it is the amount of waste generated [1], which most of will be sent to the landfill [2, 3] for disposal. In Malaysia, due to the demographic behavior, waste are sent to landfill rather than being disposed using incinerator [3]. Malaysia currently has 170 waste disposal sites, with only 14 with the status of sanitary landfill [4]. With the increase in population each year, people consumption and disposal rate are raising quicker than Malaysia's landfill utilities capability [5, 6].

Malaysian government through Ministry of Urban Wellbeing, Housing and Local Government had initiated the Separation at Source beginning from 1 September 2015 at several states in Malaysia. This require all premises to separate their solid waste at source consist of recyclable and residual waste [7]. The waste will be collected by appointed collection companies. With the implementation of this program, $17 \%$ of waste was recycled [4]. This statistics shown an expansion in the nation's recycling rate from the fact that the recycling rate in 2012 was only $10.5 \%$ [8]. Based on this, the recycling rate is expected to be at $22 \%$ by the year 2020 [9], which is still a low percentage.

Despite the effort shown by the Malaysian government, the recycling rate among Malaysian are still low. One of the considerable reason is the lack of effort to categorize the waste from the source which supposed to be done at the household level. Thus, it is necessity to educate the community to start from this 
small step. One way to promote this is by making the step easier for the community to do it, at the household level.

An automatic system that can separate the household waste item is a practical way to promote recycling among the society as it will reduce tha amount of work done by individual. A few previous work on material and waste sorting had been done [10-13]. However, some of the work are not suitable to be implemented for household application due to the size and cost. Besides that, different country have different regulation on recycling, making it difficult to have a system that will fit every regulation.

In this work, a system consist of an algorithm and hardware to automatically categorize recyclable waste is proposed. The waste will be categorize according to its material which are paper, glass, plastic and metal, which is according to Malaysian regulation for recycling. An algorithm considering the combination of the waste characteristics which are weight and size is used [14]. In this work, the algorithm is combined with a set of hardware that will automatically sort the waste according to its material.

\section{RESEARCH METHOD}

\subsection{Overall mechanism of the waste separation system}

The waste separation system in this work is devided into two parts which are classification of the items and sorting of the items. The classification of the items are based on the material of the item (plastic, metal, glass or paper) by manipulating the size and shape of the item. The classified item then will be sorted to its own category of material by servo motors that will move a set of lever. Here, the items are automatically transferred from one part to another using a conveyer belt. The overall mechanism is as shown in Figure 1 and Figure 2.

\begin{tabular}{|c|c|c|c|c|c|}
\hline $\begin{array}{c}\text { Start } \\
\text { (Enter the item } \\
\text { to be sorted) }\end{array}$ & 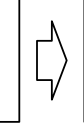 & $\left.\begin{array}{c}\text { Weight } \\
\text { measuring } \\
\text { by load cell }\end{array}\right]$ & $\begin{array}{c}\text { Servo motor moves item } \\
\text { to ultrasonic sensors via } \\
\text { conveyer belt }\end{array}$ & 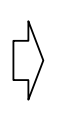 & $\begin{array}{c}\text { Shape \& size } \\
\text { determination using } \\
\text { ultrasonic sensor } \\
\end{array}$ \\
\hline End & $\begin{array}{l}\text { Servo } \\
\text { item } \\
\text { categ }\end{array}$ & $\begin{array}{l}\text { motor sorts the } \\
\text { according to its } \\
\text { ry and counted }\end{array}$ & $\begin{array}{l}\text { Infrared sensor detects } \\
\text { the arrival of item }\end{array}$ & $\beta$ & $\begin{array}{c}\text { Classification of item by } \\
\text { comparison with the } \\
\text { database }\end{array}$ \\
\hline
\end{tabular}

Figure 1. Block diagram of the overall mechanism

Ten household waste items were selected as the samples for testing the classification mechanism and separation system. The chosen items were item that can be found in most Malaysian households waste and can be classified into four different categories based on their material i.e. paper, glass, plastic and metal. The items chosen with their actual weight and dimension are summarized in Table 1.

Table 1. Items selected as sample materials

\begin{tabular}{cccc}
\hline \multirow{2}{*}{ Item } & Weight & \multicolumn{2}{c}{ Dimension } \\
\cline { 2 - 4 } & {$[\mathrm{g}]$} & $\mathrm{h} \times \mathrm{l} \times \mathrm{w}[\mathrm{cm}]$ & $\mathrm{h} \times$ topØ $\times$ bottom $\varnothing[\mathrm{cm}]$ \\
\hline Glass jam bottle & 192 & - & $12.18 \times 6.7 \times 7.14$ \\
Hard plastic cup & 21 & - & $12.2 \times 7.5 \times 5.38$ \\
Soft plastic cup & 6 & - & $15.14 \times 8.11 \times 5.83$ \\
Plastic lunchbox & 23 & $6.67 \times 16 \times 14.72$ & - \\
Tin can (small) & 28 & - & $8.83 \times 5.28 \times 5.28$ \\
Tin can (large) & 49 & - & $11.14 \times 8.83 \times 8.83$ \\
Tin can (canned drink) & 26 & - & $11.54 \times 5.91 \times 5.19$ \\
Long box (toothpaste box) & 14 & $17 \times 5 \times 3.7$ & - \\
Short box (small juice box) & 10 & $13.34 \times 5.34 \times 3.63$ & - \\
Square box & 32 & $5.84 \times 9 \times 8.5$ & - \\
\hline
\end{tabular}




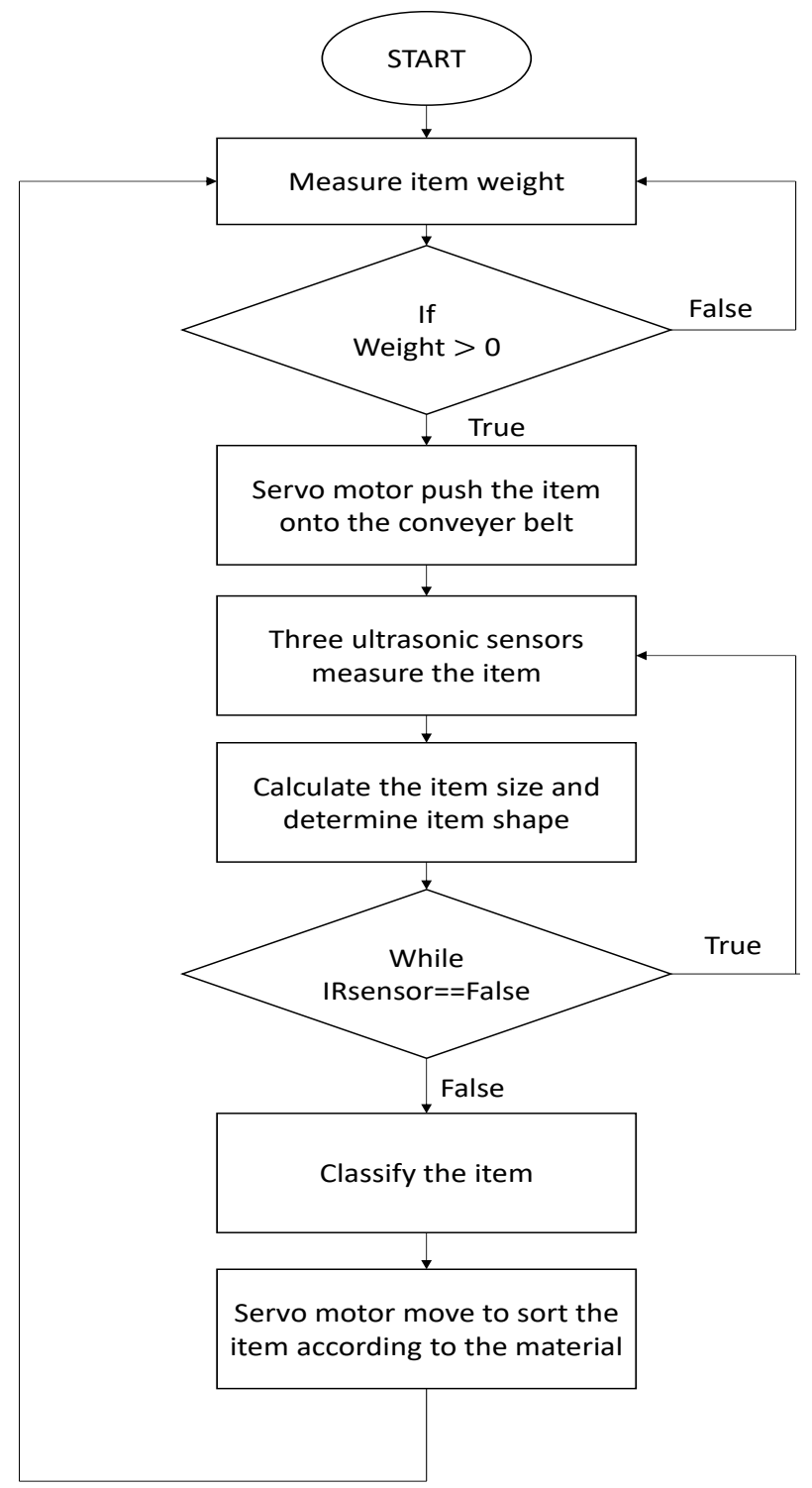

Figure 2. Flowchart of the waste separation system

\subsection{Item classification using weight and size}

In this work, the overall mechanism to classify recyclable waste according to the material was done by combining the weight and size of each item [10]. Firstly, a database of the weight and dimension are needed. The dimension of items shown in Table 1 are rounded to the nearest round numbers for the database saved in a microSD. The item will go through load cell and HX711 sensor board first. After that, the item will go through three different ultrasonic sensors to measure the dimension of the object. Then, all the measurement will be compared with the existing data in the database to classify the item according to its type. All the measured data by the weight sensor and ultrasonic sensor will be processed by Arduino microcontroller [15], and compared with the database stored in a microSD.

Ultrasonic sensor emits short and high frequency sound wave at a regular intervals. The sound wave propagates in a medium with sound velocity. The wave will be reflected if there is any object or barrier, resulting the wave to be reflected back to the sensors. In this work, the ultrasonic sensor was manipulated to measure distance between waste object and ultrasonic sensors. The information is then used to calculate the size of the object. To determine the size of waste, a combination of three ultrasonic sensors was used in this work. One of the sensor were placed at top position, and the other two were placed at the side as shown in Figure 3. Sensor 1 and sensor 2 were placed at a constant distance, $X$ between them which is $22 \mathrm{~cm}$ for this work. Meanwhile, sensor 3 was placed constant at $Y=17 \mathrm{~cm}$ from the surface. 


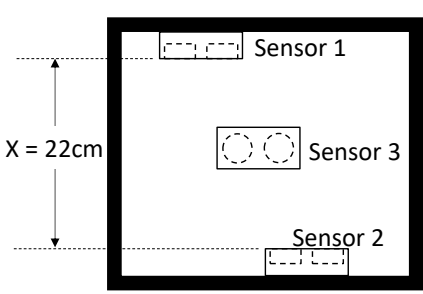

(a)

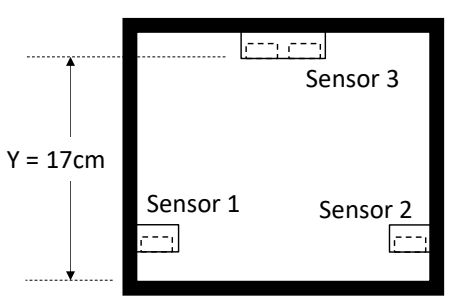

(b)

Figure 3. Ultrasonic sensors placement for item classification, (a) Top view, (b) Side view

Using this configuration of the sensors, the size of the item will be determine. The readings from sensor 1 and 2 will be combined to obtain the dimension of the item in two dimensions. Here, each of sensor 1 and sensor 2 will give the readings in four different arrays as represented by the boxes numbered as [1-4] in Figure 4. The size of item for each array is calculated using the (1).

Size of item=Constant length $(\mathrm{X})$ - measured distance by sensor 1 - measured distance by sensor 2

For example, for the size for array [0] in Figure 4 is;

Size array $[0]=22-8-8=6 \mathrm{~cm}$

Each item will be measured array by array to identify the item as the system using the list of arrays. Every item has its own size thus easier to differentiate the items. Meanwhile, the reading from sensor 3 will determine the width of the item using the formula below.

Size of item=Constant length(Y)-measured distance by sensor 3

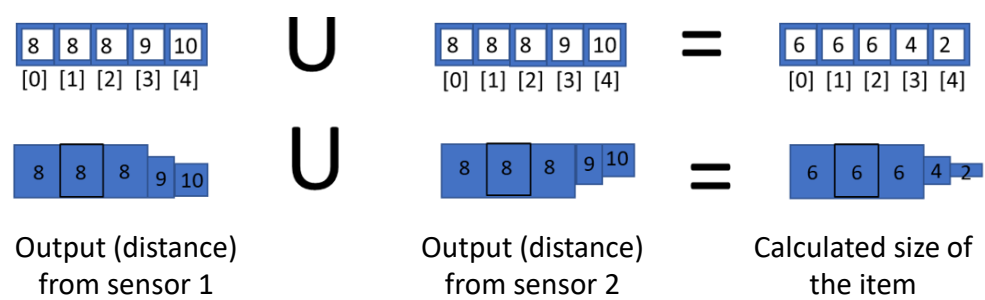

Figure 4. Array representation of ultrasonic sensor 1 and ultrasonic sensor 2

The algorithm flowchart for the item classification using the combination of the weight and size of each item is given in Appendix A to Appendix D. The flowchart for the algorithm is divided into four parts according to the data that were collected by the load cell and three ultrasonic sensors as mentioned before. The first loop of the flowchart shows the algorithm applying the weight data from the load cell is shown in Appendix A. From the measured value, the item will be classified into weight group. Then the probability of the item identified being added to Qcount array for final identification. From there, the data from ultrasonic sensor 1 and sensor 2 will be used to further classify the item, as shown in Appendix B. The same for the readings from sensor 3 shown in Appendix C. Each of the measured item will be compared to the database and added the probability into Qcount array. Finally, the maximum value in Qcount array will determine which item belong to by finding which array consist maximum value as shown in Appendix D, classifying the item into its own category, which is according to the material of the item.

\subsection{Hardware configuration for waste separation system}

The readings from the weight sensor and ultrasonic sensors are processed by an Arduino Mega as the microcontroller using the above mentioned algorithm with the hardware shown in Figure 5. The measured item then will go through an infrared sensor via the conveyer belt. This will initiate the servor motors to 
move the lever that will sort the item to one of the four compartments (metal, glass, paper and plastic). Figure 6 shows the diagram of the hardware of the waste separation system. The four compartments for the sorted items are labelled as 1, 2, 3 and 4. There are two servo motors placed at the end of the conveyer. Both servo will move to a certain angle marked as $\alpha 1$ and $\alpha 2$ and direct the classified item to the appropriate compartment as shown in Figure 7 (a)-(d). The number of item sorted to each category will be calculated and saved in the microSD as csv file.

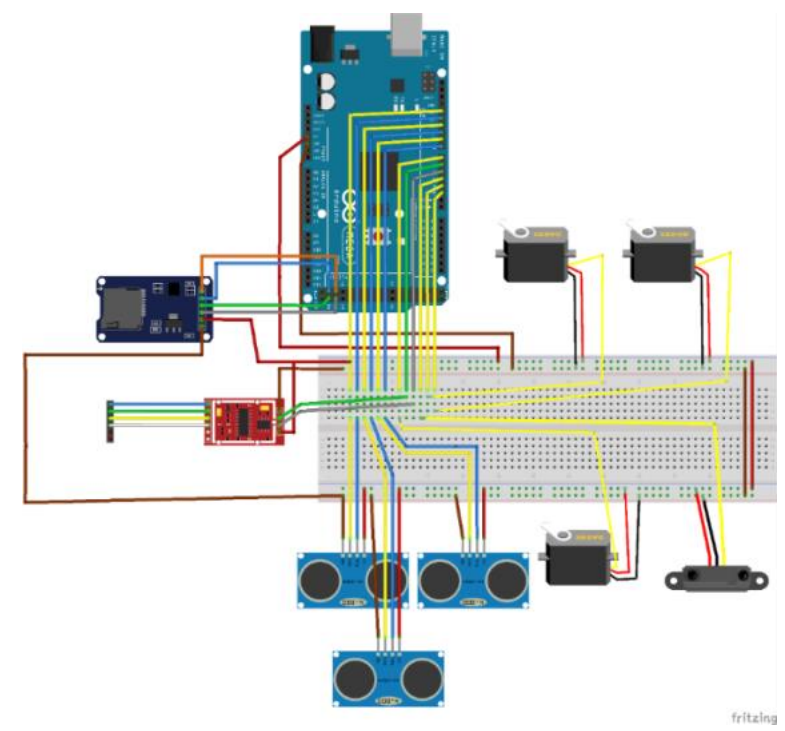

Figure 5. Circuit configuration for waste separation system

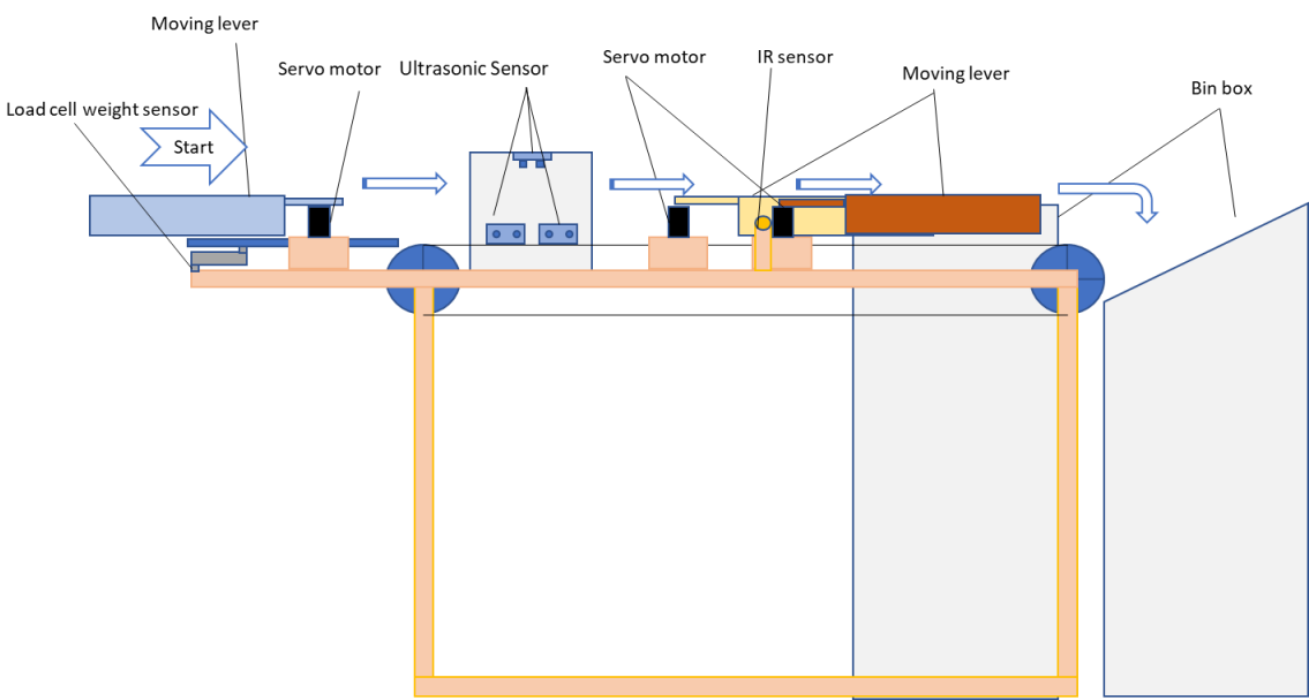

(a) 


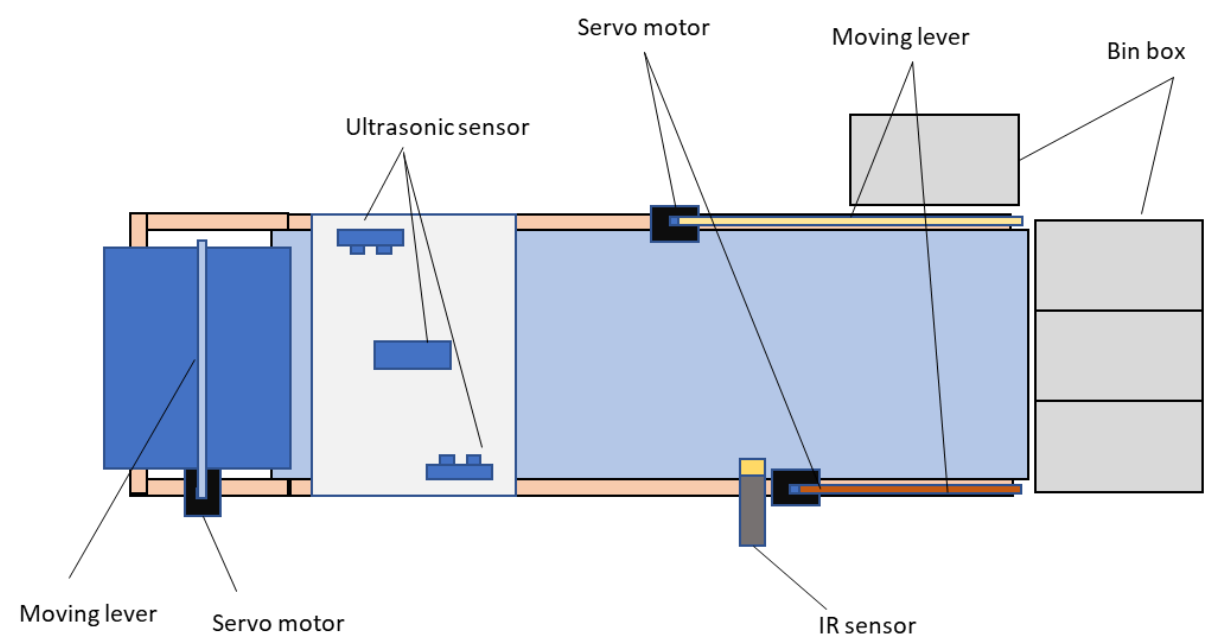

(b)

Figure 6. Waste separation system hardware, (a) Side view, (b) Top view

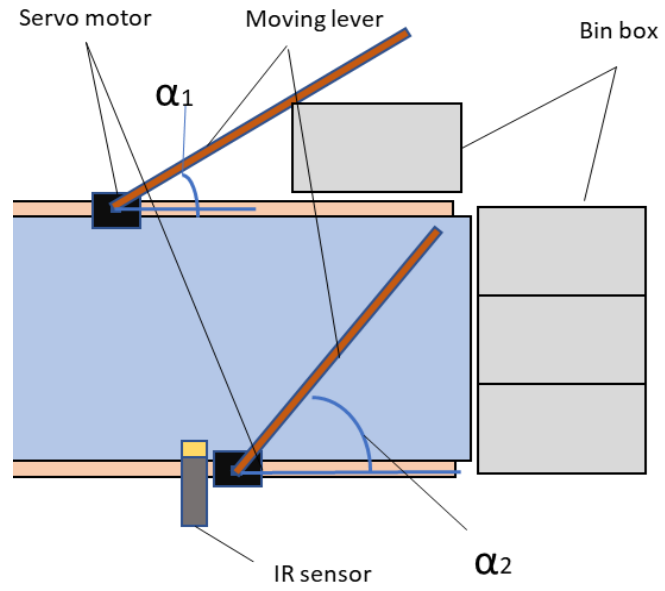

(a)

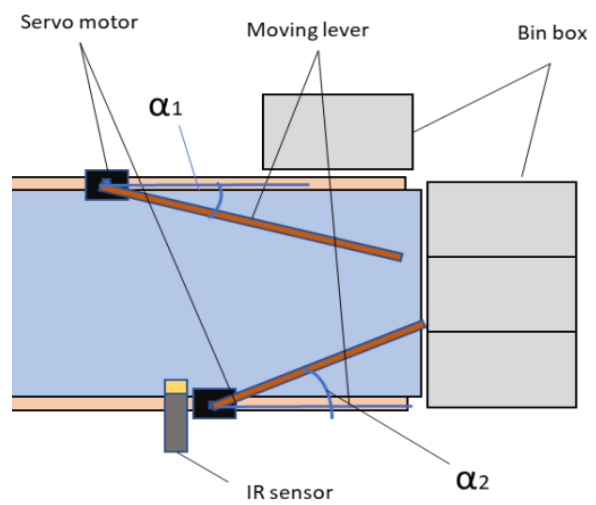

(c)

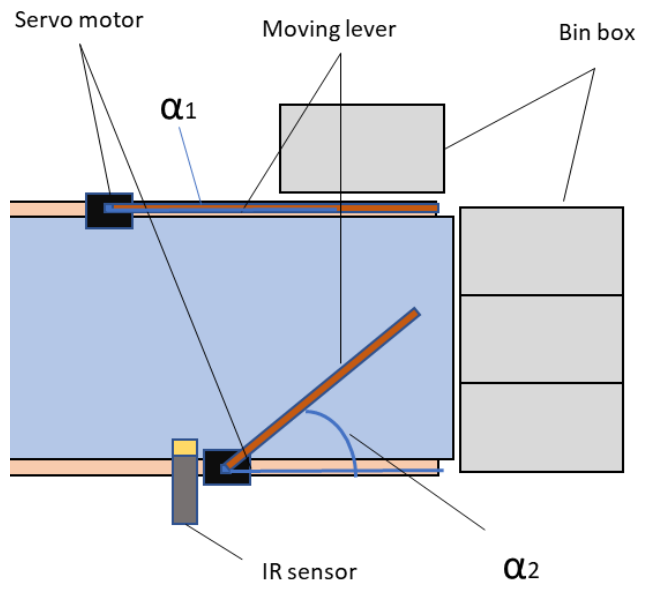

(b)

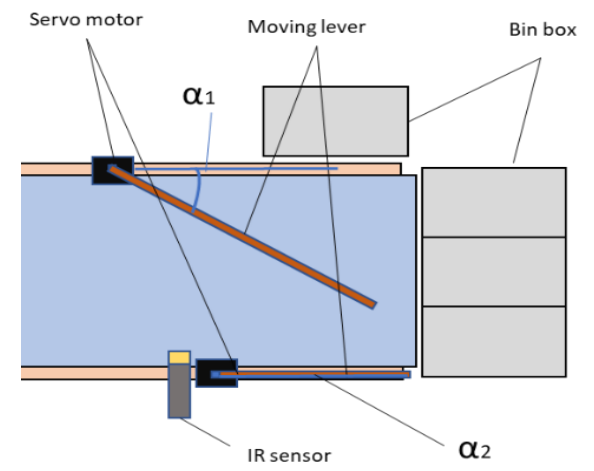

(d)

Figure 7. Lever position for compartment 1-4 


\section{RESULTS AND ANALYSIS}

Figure 8 shows the prototype of the waste separation system. The accuracy of the system was checked by running an accuracy test for each of the item chosen. Here, each item were tested ten times and the result was recorded as whether the item is correctly being classified into paper, glass, plastic and metal or not. The result for the test is summarized in Table 2 . T1, T2, .., T10 represent test number 1 until 10 , meanwhile 1 indicates that the item is correctly categorized and 0 indicates that the item is categorized wrongly. Figure 9 shows the accuracy in percentage.

From the result, it can be seen that most of the item were successfully being categorized appropriately to its own category using the presented algorithm. However, there are a few failed classification for some items, namely the soft plastic cup, long box (toothpaste box), small box (small juice box). This can be explained by the physical of the item which is easily deformed due to its nature. This will affect the readings that were collected by the three ultrasonic sensors. For some item like the soft plastic cup, the weight which is too low is also one of the reason to the low accuracy of categorization. The small weight might not be captured by the weight sensor, but instead the weight from the pressure while placing the item is recorded.
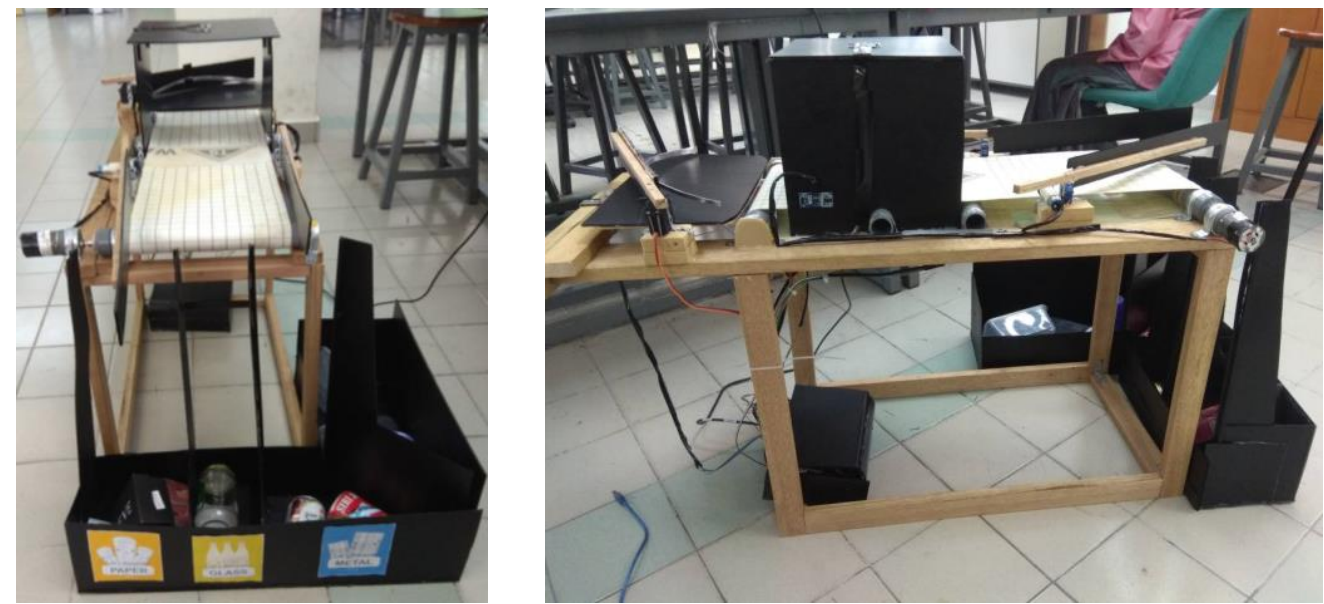

Figure 8. Prototype of the waste separation system

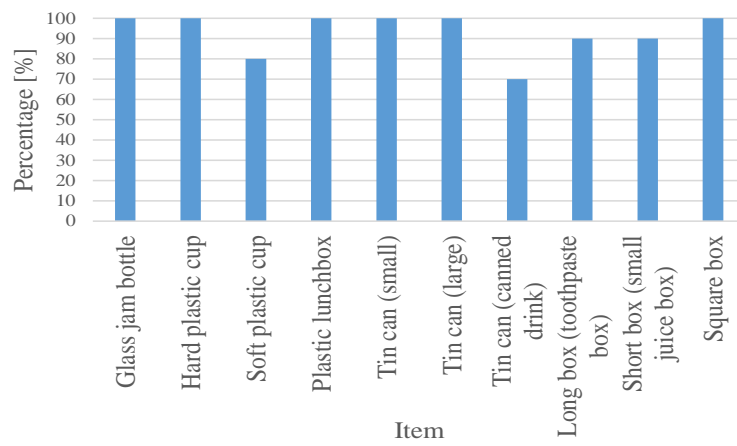

Figure 9. Percentage of accuracy

For the counting mechanism, each of all ten items were tested once, in the sequence as shown in Table 2. The result for counting is shown in Table 3. Here it can be seen that total of three plastic items were detected by the system. This number is accurate where three of the sample item (hard plastic cup, soft plastic cup and plastic lunchbox) are made of plastic. On the other hand, the reading for glass is one, which is accurate as the only glass made item is the glass jam bottle. This counted results are saved in the external microSD as csv file. 
Table 2. Accuracy test result

\begin{tabular}{cccccccccc}
\hline Item & T1 & T2 & T3 & T4 & T6 & T7 & T8 & T9 & T10 \\
\hline Glass jam bottle & 1 & 1 & 1 & 1 & 1 & 1 & 1 & 1 & 1 \\
Hard plastic cup & 1 & 1 & 1 & 1 & 1 & 1 & 1 & 1 & 1 \\
Soft plastic cup & 1 & 0 & 1 & 1 & 0 & 1 & 1 & 1 & 1 \\
Plastic lunchbox & 1 & 1 & 1 & 1 & 1 & 1 & 1 & 1 & 1 \\
Tin cal (small) & 1 & 1 & 1 & 1 & 1 & 1 & 1 & 1 & 1 \\
Tin can (large) & 1 & 1 & 1 & 1 & 1 & 1 & 1 & 1 & 1 \\
Tin can (canned drink) & 1 & 0 & 0 & 1 & 1 & 1 & 0 & 1 & 1 \\
Long box (toothpaste box) & 1 & 1 & 1 & 1 & 0 & 1 & 1 & 1 & 1 \\
Short box (small juice box) & 1 & 1 & 1 & 1 & 1 & 1 & 0 & 1 & 1 \\
Square box & 1 & 1 & 1 & 1 & 1 & 1 & 1 & 1 & 1 \\
\hline
\end{tabular}

Table 3. Result for counting mechanism

\begin{tabular}{ccccc}
\hline Item & Plastic & Metal & Glass & Paper \\
\hline Glass jam bottle & 0 & 0 & 1 & 0 \\
Hard plastic cup & 1 & 0 & 1 & 0 \\
Soft plastic cup & 2 & 0 & 1 & 0 \\
Plastic lunchbox & 3 & 0 & 1 & 0 \\
Tin cal (small) & 3 & 1 & 1 & 0 \\
Tin can (large) & 3 & 2 & 1 & 0 \\
Tin can (canned drink) & 3 & 3 & 1 & 0 \\
Long box (toothpaste box) & 3 & 3 & 1 & 1 \\
Short box (small juice box) & 3 & 3 & 1 & 2 \\
Square box & 3 & 3 & 1 & 3 \\
Max & 3 & 3 & 1 & 3 \\
\hline
\end{tabular}

\section{CONCLUSION}

In this work, recyclable waste items were categorized based on its material by making use of the weight and size of the item. The weight sensor and ultrasonic sensors were used to measure the parameter, and an algorithm was developed to classify the items based on available database. The algorithm was combined with a set of hardware for the automation of movement process of the waste and also to categorize the item to their appropriate group of material. The developed system was proven to be applicable to categorize item to different categories which are paper, glass, plastic and metal. Hence, this approach presented in this paper can be an option in differentiating and categorizing different item, as an additional or replacement to other approaches such as image processing.

However, there might still be some drawback of the algorithm such as the need of a database. In this work, only ten items were tested, and from the observation, it can be conclude that larger number of item types might increase the complexity of the algorithm, apart from the need of an extensive database. Besides the algorithm, improvements are also possible on the hardware part, such as the microcontroller with better performance and connectivity. Adding different types on sensors also should increase the variety of the waste item that can be catered. Application of Internet of Things with this system is also anticipated, as it will ensure a continuation flow in recycling process.

\section{ACKNOWLEDGEMENTS}

This research has been supported by Malaysian Ministry of Higher Education Research Grant, RAGS15-063-0126.

\section{REFERENCES}

[1] M. O. Saeed, M. N. Hassan, M. A. Mujeebu, "Assessment of municipal solid waste generation and recyclable materials potential in Kuala Lumpur, Malaysia," Waste Management, vol 29, no 7, pp. 2209-2213, 2009.

[2] R. A. Begum, C. Siwar, J. J. Pereira, A. H. Jaafar, "Factors and values of willingness to pay for improved construction waste management - A perspective of Malaysian contractors," Waste Management, vol. 27, no. 12, pp. 1902-1909, 2007.

[3] S. H. Fauziah, "Landfills in Malaysia: Past, Present and Future," 1st International Conference on Final Sinks, vienna, pp. 1-9, 2010

[4] F. Aziz, "Despite govt efforts, only 17 per cent of Malaysians recycle," New Straits Times, Putrajaya, 18 May 2016.

[5] S. N. Syed Ismail, L. Abd Manaf, "The challenge of future landfill : A case study of Malaysia," Journal of Toxilogy and Environmental Health Science, vol. 5, no. 6, pp. 86-96, 2013. 
[6] J. S. tey, K. C. Goh, H. H. Goh, "Challenges in selecting a sustainable landfill site in Malaysia," MATEC Web of Conferences, vol. 47, no. 05021, 2016.

[7] "SEPARATION-AT-SOURCE.” [Online]. Available: http://www.kpkt.gov.my/separationatsource/en/. [Accessed: 23-Nov-2017].

[8] V. E.-L. GOMES, "Country's recycling rate on track, says minister," Malay Mail, Kuala Lumpur, 27-Oct-2016.

[9] Y. C. Moh and L. Abd Manaf, "Overview of Household Solid Waste Recycling Policy Status and Challenges in Malaysia," Resources, Conservation and Recycling, vol. 82, pp. 50-61, 2014.

[10] G. Richard, A. R. Salama, K. Medles, C. Lubat, S. Touhami and L. Dascalescu, "Experimental and Numerical Study of the Electrostatic Separation of Two Types of Copper Wires From Electric Cable Wastes," in IEEE Transactions on Industry Applications, vol. 53, no. 4, pp. 3960-3969, July-Aug. 2017.

[11] B. M. Chinnathurai, R. Sivakumar, S. Sadagopan and J. M. Conrad, "Design and implementation of a semi-autonomous waste segregation robot," SoutheastCon 2016, Norfolk, VA, 2016, pp. 1-6.

[12] M. O. Rahman, A. Hussain, E. Scavino, M. A. Hannan and H. Basri, "Object identification using DNA computing algorithm," 2012 IEEE Congress on Evolutionary Computation, Brisbane, QLD, 2012, pp. 1-7.

[13] M. Nawrocky, D. C. Schuurman and J. Fortuna, "Visual sorting of recyclable goods using a support vector machine," CCECE 2010, Calgary, AB, 2010, pp. 1-4.

[14] M. A. Rahmad, N. S. Midi, S. A. Zaini, S. H. Yusoff and S. Y. Mohamad, "Material Classification of Recyclable Waste using the Weight and Size of Waste," 2018 7th International Conference on Computer and Communication Engineering (ICCCE), Kuala Lumpur, 2018, pp. 44-49.

[15] T.S. Gunawan, I.R.H. Yaldi, M.Kartiwi, N. Ismail, N.F. Za'bah, H. Mansor, A.N. Nordin, "Prototype design of smart home system using internet of things, "Indonesian Journal of Electrical Engineering and Computer Science, vol. 7, no. 1, pp. 107-115, July 2017.

\section{BIOGRAPHIES OF AUTHORS}
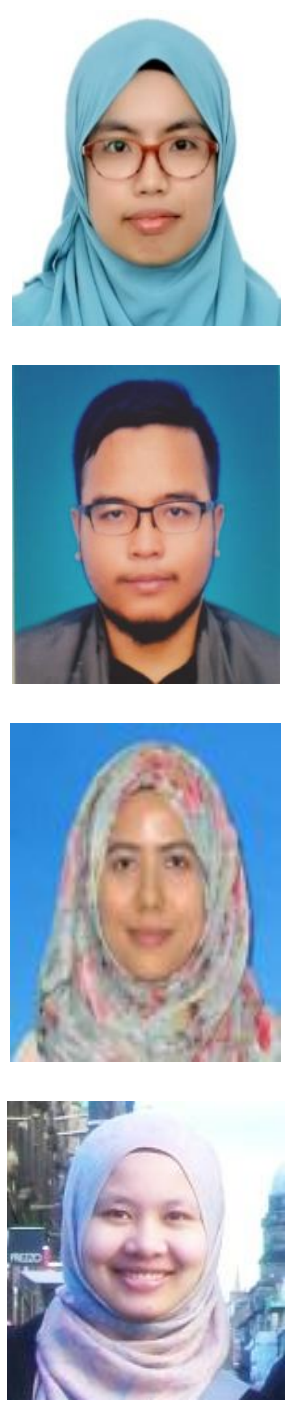

Nur Shahida Midi received a MEng. Degree in Electical and Electronic System Engineering and a Ph.D Degree in Engineering (Science and Technology) from Tokai University, Japan in 2012 and 2015 respectively. She has been appointed as an Assistant Professor in the Department of Electrical and Computer Engineering, Faculty of Engineering, International Islamic University of Malaysia (IIUM). Her current research interests include high voltage engineering, electrical power engineering, Internet of Things (IoT) and waste management.

Muhammad Aizat Rahmad received his BEng degree in Electronics - Conputer Information Engineering from the International Islamic University in 2018. He started his career as Drive Test Engineer (DTE) at Propel Network Sdn. Bhd. He is currently an IT Engineer in Reactive Service Team (RST) at DXC Technology, Cyberjaya, Malaysia.

Siti Hajar Yusoff received a MEng. Degree ( $\left(1^{\text {st }}\right.$ Class Hons) in Electrical Engineering from the University of Nottingham, UK and a Ph.D. degree in Electrical and Electronic Engineering from the University of Nottingham, U.K., in 2009 in 2014, respectively. She has been appointed as an Assistant Professor in the Department of Electrical and Computer Engineering, Faculty of Engineering, International Islamic University Malaysia (IIUM). Her current research interests include IoT (Internet of Things), Smart cities, non-linear control, renewable energy, wireless dynamic charging in electric cars.

Sarah Yasmin Mohamad received a MEng. degree in Communication and Computer Engineering from the Universiti Kebangsaan Malaysia (UKM) and a Ph.D. degree in Electrical and Electronic Engineering from the Queen's University Belfast, Belfast, U.K., in 2011 in 2015, respectively. She has been appointed as an Assistant Professor in the Department of Electrical and Computer Engineering, Faculty of Engineering, International Islamic University Malaysia (IIUM). Her current research interests include antennas and wave propagation and wireless communication systems. 


\section{APPENDIX}

Algorithm Flowchart (Part 1)

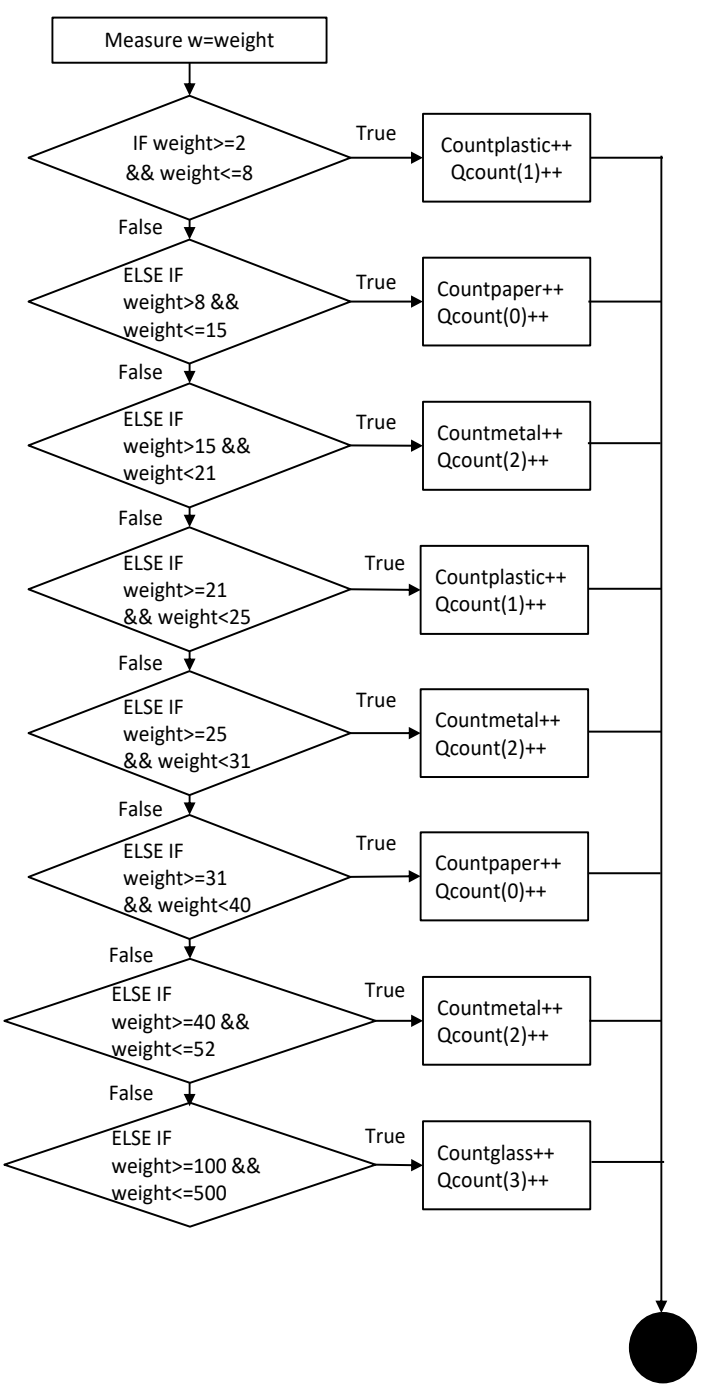

Algorithm Flowchart (Part 2)

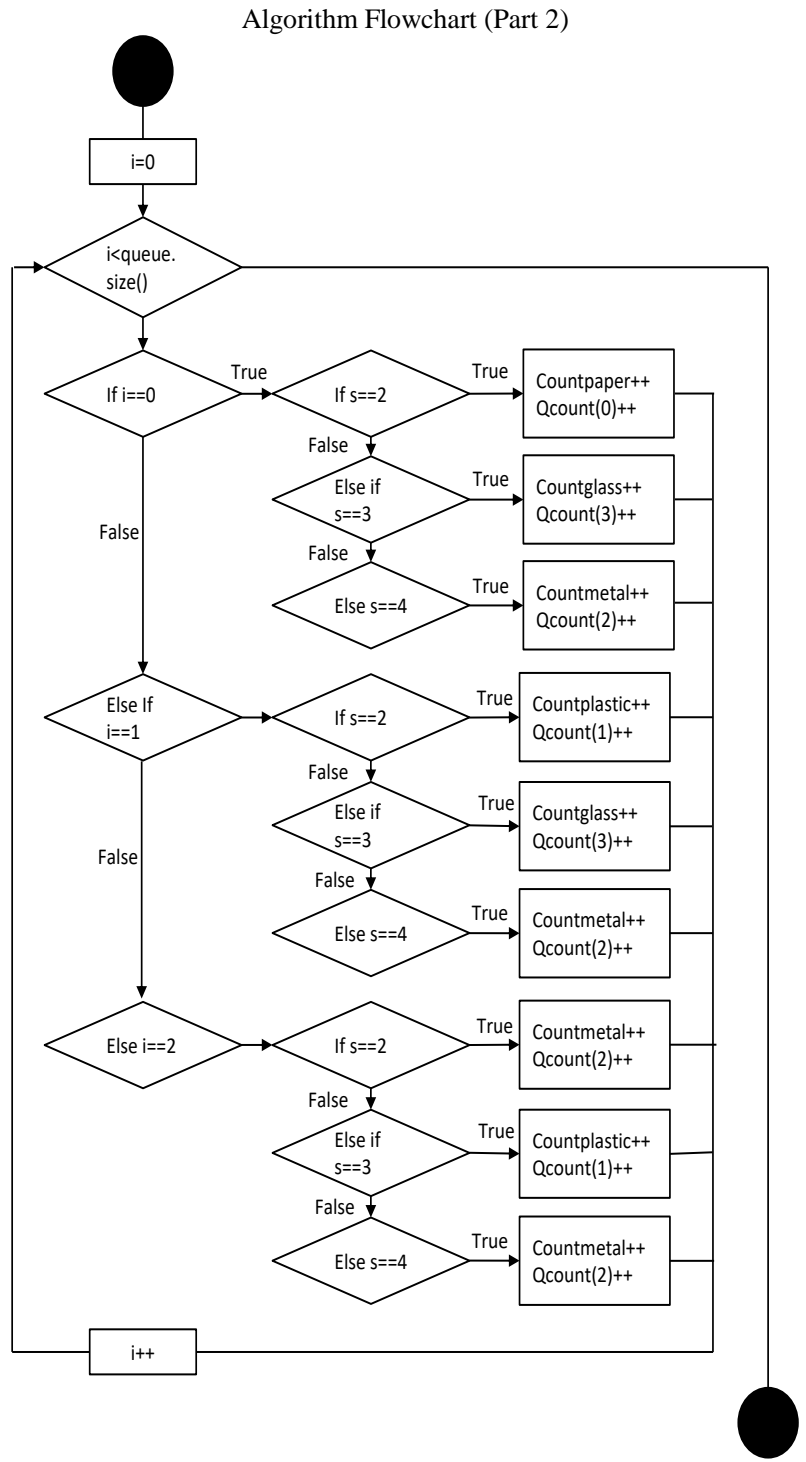




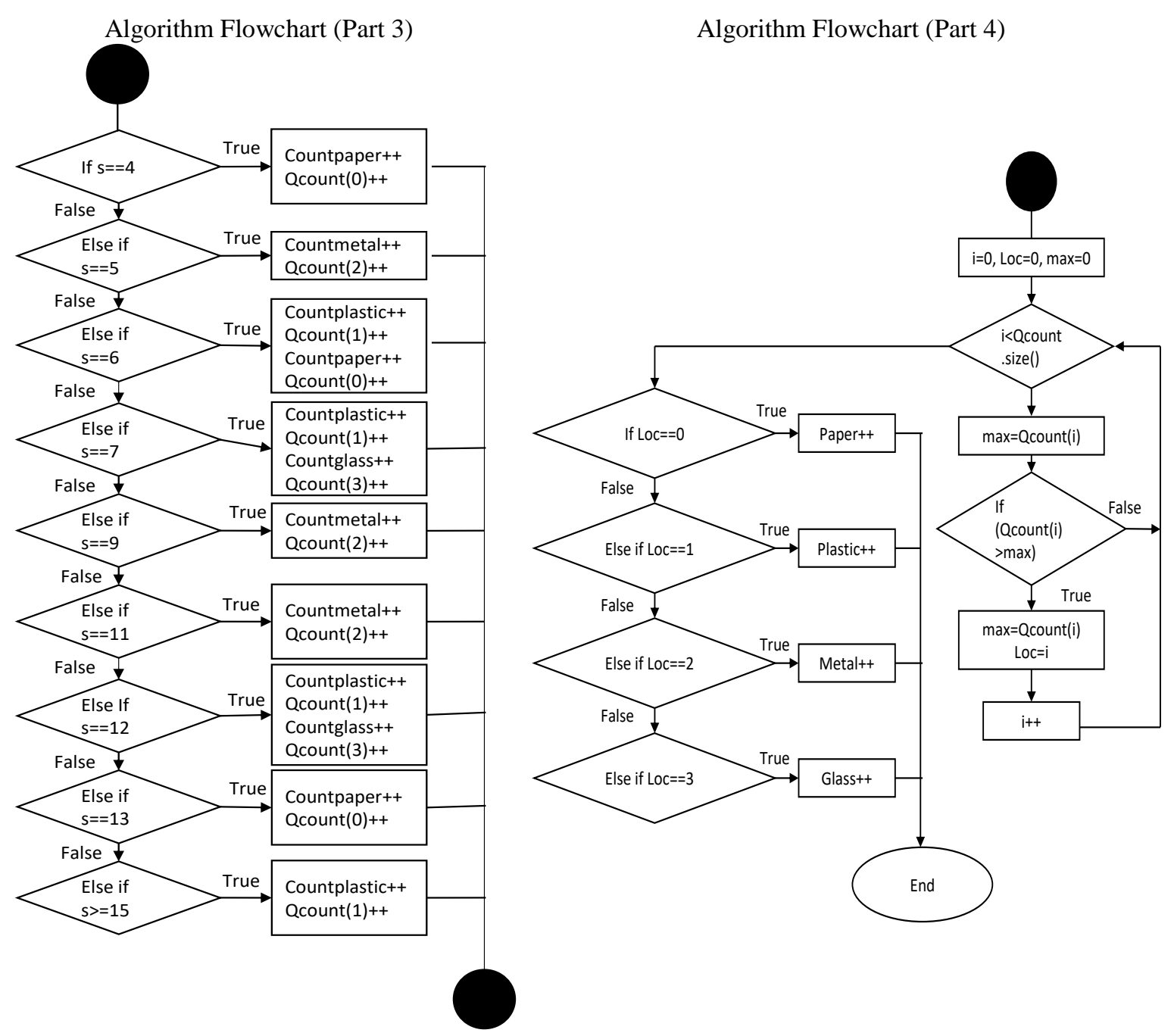

